\title{
X-RAY AND INFRA-RED INVESTIGATIONS OF THE MOLECULAR STRUCTURE OF LIQUID CRYSTALS.*
}

BY

J. STEPH. VAN DER LINGEN, B.A., Ph.D., F.P.S. (London).

Government Research Fellow, James Buchanan Johnson Scholar, Johns Hopkins University, Member of the Institute.

X-RAY INVESTIGATION.

IT has been shown by Lehmann and others that the optical properties of liquid crystals ${ }^{1}$ are influenced by the surfaces between which the liquids are enclosed, so much so that Lehmann contends that "liquid crystals" have a space-lattice when they are enclosed between "similar and similarly orientating crystalline plates."

In order to bring the substance under investigation into direct contact with similarly orientating crystalline plates, a thin rectangular plate of mica was clamped along one edge and carefully split open from the opposite edge into the form of a wedge. Some finely powdered p. azoxyanisole was placed in this wedge. This wedge was gradually heated on a copper plate, and after the crystalline powder had melted the air bubbles were squeezed out at the open end. On cooling the enclosed layer of p. azoxyanisole presented a fairly uniform crystalline appearance under the microscope. This preparation was placed in the heating spirals, ${ }^{2}$ and a series of photograms were obtained when. the substance was in the solid, plastic and liquid states.

Each photogram gives the mica "point pattern" and the pattern of the substance between the mica plates. By comparing these patterns one can eliminate the mica pattern and thus obtain the pattern due to the substance only.

On transmitting a parallel pencil of $\mathrm{X}$-rays through the thin solidified layer of $p$. azoxyanisole the pattern showed several fairly large (about I mm. diameter), irregularly shaped spots which indicated that the crystalline layer is made up of small crystal units of about $\mathrm{I} \mathrm{mm}$. in cross-section.

* Communicated by Dr. J. S. Ames.

${ }^{1}$ See this Journal page 65I, 192I.

2 Ibid. 
On heating the cell the crystalline layer becomes plastic. This can be tested by viewing the layer through a microscope and observing the sliding when a knitting needle is lightly pressed against one of the plates. In this state the photogram clearly shows that the substance still possesses a space-lattice. It gives a point pattern consisting of a few irregularly shaped spots, which do not give any indication of the type of crystal symmetry.

On increasing the temperature of the cell until the layer became an anisotropic liquid, and transmitting a parallel pencil of $\mathrm{X}$-rays through it, a new type of pattern was obtained after an exposure of forty hours. It consists of a series of faint horizontal lines, which are about I $\mathrm{mm}$. broad for those lines which pass through the central spot. Farther off they are fainter, thinner, and more closely spaced. If this phenomenon be due to diffraction from parallel layers of lamellar molecules the spacing between the molecules must be of the order of $40 \mathrm{~A}$ units. This point wiil be further investigated in the near future.

\section{INFRA-RED INVESTIGATIONS.}

Abney and Festing, Julius, Puccianti, Aschkinass, Rubens, Coblentz and others have shown that radicals have distinctive absorption spectra, moreover Julius, Puccianti and subsequently Coblentz have shown that the bonding of atoms in isomeric compounds has a great influence on the absorption spectrum whereas stereomeric compounds investigated by Coblentz show no change in their absorption spectra. ${ }^{3}$

Angström, Rubens and Aschkinass showed that the spectra of liquids and their vapors are identical, and in $1906 \mathrm{P}$ fund showed that the selective reflections from solid and from molten crystals are identical, whereas the spectrum of sulphuric acid changes with dilution. ${ }^{4}$

From the above-mentioned investigations it appears that any change in the molecule of a compound will be accompanied by a change in the absorption spectrum of the compound.

This method of investigation enables one to determine whether the absorbing mechanism of the molecule changes when it is subjected to physical changes. In order to find whether any change takes place in the molecule of those solids which give rise to liquid

${ }^{3}$ Coblentz: Investigations of Infra-red Spectra, Carnegie Publication I905.

-Astrophysical Journal, 24, I-19, 1906. 
crystals in the molten state, a heating apparatus was constructed out of two concentric hollow cylinders: The inner one having a flange and a corresponding plate between which two rock salt plates containing the substance under investigation could be clamped. The outer cylinder was wound with resistance wire between asbestos sheeting. Radiations from a Nernst glower were brought to a focus by a mirror on the cell, and a second mirror projected this image on the slit of the spectroscope consisting of a Wadsworth mirror and rock salt prism arrangement

FIG. I.

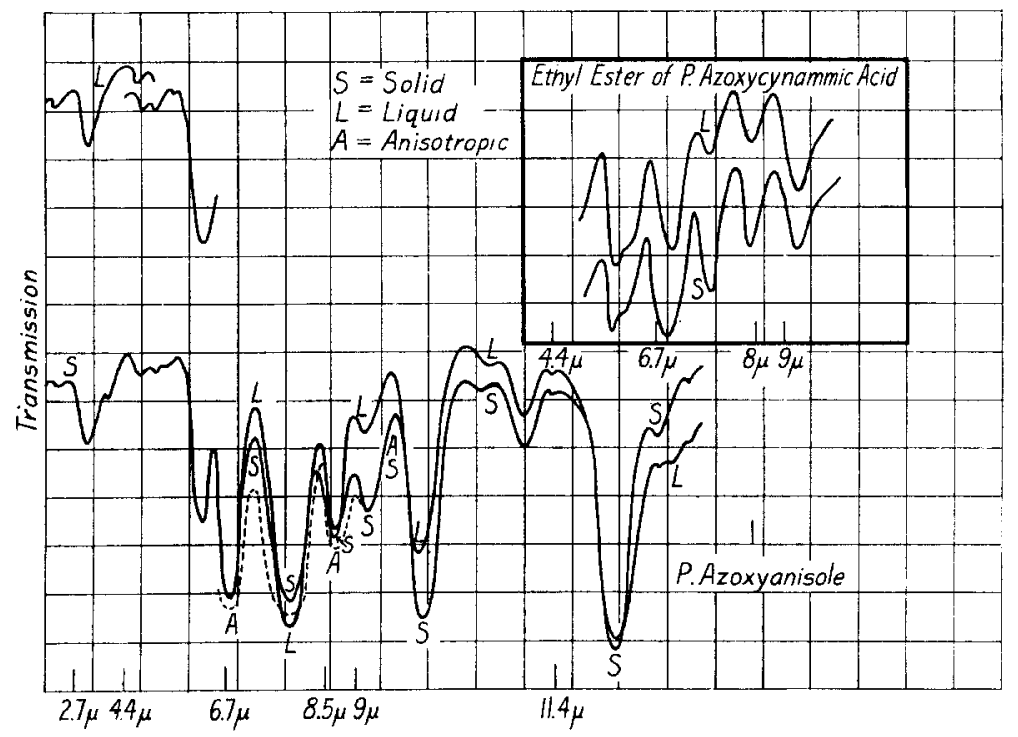

Transmission curves of p.azoxyanisole and of ethyl ester of p. azoxycynammic acid.

and a delicate thermocouple and galvanometer. A milled-head connected to a tape served to rotate the prism.

The method of procedure was to read off the galvanometer deflection when the cell was removed and when the radiations had passed through the cell and from these readings the percentage transmission was calculated. Beyond $3^{\mu}$ a long series of readings could be obtained without changing the slit width. This enables one to use the same portion of the cell throughout, whereas at shorter wave-lengths the cell had to be removed at frequent intervals to obtain the "air curve" for the same slit width. This method does not give concordant results with regard to percent- 
ages as a small change in thickness of the layer penetrated shows a marked influence on the transmission. It does not, however, affect the positions for minima transmission.

For this work p. azoxyanisole and p. azoxycynammic acid ethyl ester were used. ${ }^{5}$ If any change takes place in the bonding of the atoms in the radicals one would expect to find a marked change in the spectra in the region $6 \mu$ to Io $\mu$. From the figures it appears that the spectra of the solid, the anisotropic liquid and the amorphous liquid are the same, hence no change has taken place in the bonding of the atoms in the radicals. If changes in space-lattices be due to changes in the molecules of polymorphous substances, then these changes are not due to changes in the radicals but to a spatial rearrangement of the component parts of the molecules.

In conclusion I wish to express my sincere thanks to Professor Pfund for placing his apparatus at my disposal and also for his help and advice.

Baltimore, MD.

JULY 6, I92I.

Electrolytic Oxidation of the Leuco-base of Malachite Green.-The manufacture of standard coal-tar colors involves so many points of difficulty that extensive and minute research is required to obtain constancy in the product. Advance sheets of the forthcoming (4oth) meeting of the American Electrochemical Society describe experiments made with a view of substituting electrolytic methods for the use of lead peroxide in making malachite green. The investigation was conducted by A. Lowy and E. H. Haux, in the department of chemistry, University of Pittsburgh. The commercial method with lead peroxide is to add this substance in slight excess, filter out the insoluble lead compound and precipitate such lead as has passed into solution by means of sodium sulphate. The equations for the reactions involved are given in detail. Experiments with an electric current showed that no satisfactory result can be obtained without a catalyst, and uranyl nitrate was found to be the best of those tried. A nichrome gauze anode in dilute sulphuric acid at $85^{\circ} \mathrm{C}$. was used. A moderately high temperature is essential. The gauze dissolves in the acid which makes its use objectionable. The usual method with lead peroxide is carried out in the cold.

H. L.

${ }^{5}$ These substances were kindly placed at my disposal bv Professor C.W. v.d. Merwe, of Stellenbach University, South Africa. 